\title{
Zenker's diverticulum: endoscopic versus surgical approach. Which is better? Experience in the General Hospital of Mexico Dr. Eduardo Liceaga
}

\author{
Divertículo de Zenker. Manejo endoscópico contra técnica abierta. ¿Cuál es mejor? \\ Experiencia en el Hospital General de México Dr. Eduardo Liceaga
}

\author{
Ansony R. Godinez-Vidal*, Luis M. Hurtado-López, Erich O.P. Basurto-Kuba, \\ Edgar Montes de Oca-Durán, Francisco R. Higuera-Hidalgo and Agustín Etchegaray-Donde \\ Department of General Surgery, Hospital General de México Dr. Eduardo Liceaga, Mexico City, Mexico
}

\begin{abstract}
Background: Zenker diverticulum is a rare disease in the general population. Its treatment can be carried out by either an endoscopic or surgical approach. Objective: To report the experience in the management of the Zenker diverticulum in a tertiary education center. Methods: Retrospective, cross-sectional, descriptive study in which the files of all patients with diagnosis of Zenker diverticulum were analyzed from the formation of the upper digestive tract clinic of the General Hospital of Mexico Dr. Eduardo Liceaga. Results: We found 14 cases with diagnosis of Zenker diverticulum, 10 treated with transoral technique and 4 for open surgery. Three recurrences in the transoral technique, no relapse with open technique. In terms of complications, one dental lesion was presented in the technique transoral, and one esophageal fistula in open surgery, managed with a nasojejunal tube placed by endoscopy until the spontaneous closure of said fistula. Conclusions: Transoral stapling is a technique with good aesthetic results. However, in our experience, it has a greater recurrence than open surgery, which is why we must carry out a long-term follow-up of our patients.
\end{abstract}

KEY WORDS: Zenker diverticulum. Transoral management. Endoscopic management. Open surgery.

\section{Resumen}

Introducción: El divertículo de Zenker es una enfermedad rara en la población general. Su tratamiento puede llevarse a cabo mediante un enfoque endoscópico o quirúrgico. Objetivo: Reportar la experiencia en el manejo del divertículo de Zenker en un centro de enseñanza de tercer nivel. Métodos: Estudio retrospectivo, transversal, descriptivo, en el que fueron analizados los expedientes de todos los pacientes con diagnóstico de divertículo de Zenker desde la formación de la clínica de tracto digestive superior del Hospital General de México Dr. Eduardo Liceaga. Resultados: Se encontraron 14 casos con diagnóstico de divertículo de Zenker, 10 tratados con técnica transoral y 4 por cirugía abierta. Se presentaron tres recidivas en la técnica transoral y ninguna con la técnica abierta. En cuanto a las complicaciones, hubo una lesión dental con la técnica transoral y una fistula esofágica con cirugía abierta, que fue manejada con sonda nasoyeyunal colocada por endoscopia hasta el cierre espontáneo de la fístula. Conclusión: El grapado transoral es una técnica con buenos resultados estéticos, pero en nuestra experiencia presenta mayor recurrencia que la cirugía abierta, por lo que debemos realizar un seguimiento a largo plazo de nuestros pacientes.

PALABRAS CLAVE: Divertículo de Zenker. Manejo transoral. Manejo endoscópico. Cirugía abierta.

\author{
Correspondence: \\ *Ansony R. Godinez-Vidal \\ Dr. Balmis, 148 \\ Col. Doctores, Del. Cuauhtémoc \\ C.P. 06726, Ciudad de México, México \\ E-mail: ansony.rgv@gmail.com
}

Date of reception: 05-03-2018

Date of acceptance: 17-04-2018

DOI: 10.24875/CIRUE.M18000037
Cir Cir. 2018;86:215-220

Contents available at PubMed www.cirugiaycirujanos.com 


\section{Introduction}

Zenker's or hypopharyngeal diverticulum is a true herniation of the esophageal mucosa through a zone of weakness known as the "Killian anatomical triangle", located between the oblique fibers of the lower constrictor of the pharynx and the transverse fibers of the cricopharyngeal muscle. It is also called a false diverticulum because its walls lack muscle tissue, as it is only formed by mucosa and submucosa'. Although it was first described by Abraham Ludlow in $1764^{2}$, it owes its name to German anatomist Friedrich Albert von Zenker, who in 1877 made the first detailed description of these diverticula ${ }^{3}$.

Zenker's diverticulum is a rare disease in the general population. Its treatment can be carried out by endoscopic or surgical approach. Current literature favors the use of several endoscopic procedures over external surgical techniques, arguing that endoscopic approaches reduce intraoperative time and anesthesia, hospital length of stay and the days until oral diet is resumed. However, such techniques often have higher rates of symptomatic recurrence and require additional interventions. Due to our experience with open and endoscopic diverticulectomy, we tried to compare both these procedures. At Hospital General de Mexico, a review of 6500 medical records was carried out, where three cases were mentioned; therefore, we think that in Mexico it is less common than in the European population, where it is more frequent in men and in older people (seventh to ninth decades of life) ${ }^{4}$.

\section{Pathology}

When the diverticulum wall is examined, it is found to be thin, but resistant. It consists of mucosal tissue, some isolated muscle fibers and a fibrous layer. Muscle fiber alterations are often found in the cricopharyngeal muscle, which in parts show signs of degeneration and replacement by fibroadipose tissue ${ }^{5}$. Whether these alterations are the cause or the consequence of muscle dysfunction is not known. The diverticulum floor, constituted of squamous epithelium, can show both acute and chronic inflammatory changes, with cellular infiltrates and increased vascularity.

\section{Pathophysiology}

The increase in endopharyngeal pressure caused by the protrusion of the mucosa through the Killian triangle may have its origin in an asynchronism between the contraction of the walls and the relaxation of the upper esophageal sphincter. This hypothesis is the most acceptable, given that the incidence of this diverticulum is higher in people older than 50 years, who usually show some degree of deterioration in neuromuscular coordination.

Other pathophysiological mechanisms have been proposed, such as an absence of cricopharyngeal relaxation (achalasia) ${ }^{6}$, isolated hypertension thereof and influence of gastroesophageal reflux, which causes cricopharyngeal spasm, taking into account that hiatal hernia with reflux is associated with the diverticulum in a proportion ranging from 39 to $50 \%$. The relationship of Zenker's diverticulum with hiatal hernia and reflux is unclear; recently, induced acid reflux in laboratory animals ${ }^{8}$ has been postulated to cause a shortening of the esophagus, with this generating strong traction on the cricopharyngeal muscle and separating it from the inferior constrictor of the pharynx and expanding the weakness zone where the diverticulum would emerge from. This is an interesting hypothesis that would open the door for more research and for extrapolating its conclusions to humans ${ }^{9}$.

The reality is that there is not a regular frequency in the concomitance of both pathologies, and it is a fact of observation that, in patients with large diverticula, significant associated reflux is not always demonstrated. Some patients with reflux have also been observed to improve after the diverticulum is removed and the cricopharyngeal muscle is sectioned, without aspiration phenomena being observed in these cases, as it would be expected if the sphincter exerted a barrier function ${ }^{10}$.

\section{Objective}

This study reports the experience in the management of Zenker's diverticulum at Hospital General de Mexico Dr. Eduardo Liceaga.

\section{Methods}

Cross-sectional, retrospective, descriptive study, where the records of all patients diagnosed with Zenker's diverticulum at Hospital General de Mexico Dr. Eduardo Liceaga upper gastrointestinal tract clinic were analyzed.

\section{Results}

Fourteen cases diagnosed with Zenker's diverticulum were found, out of which 10 were treated with 
transoral technique and four with open surgery. There were three relapses with the transoral technique and one with the open technique. As for complications, there was a dental injury with the transoral technique and an esophageal fistula with open surgery, which was managed with a nasojejunal tube placed by endoscopy until spontaneous closure.

\section{Discussion}

This is a pathology that can be diagnosed even in the outpatient setting, since the presence of halitosis and increased volume of the left side of the neck suggest the presence of Zenker's diverticulum; some patients may develop recurrent pneumonia. In our clinic, few patients arrived with halitosis; most of them had oropharyngeal dysphagia due to the compression caused by the diverticulum in the proximal portion of the esophagus, as a consequence of the reduction of its lumen, and food regurgitation. After interrogation and physical examination, if there is diagnostic suspicion, the first diagnostic support study is an esophagus-gastroduodenal series with water-soluble medium swallow, where the diverticulum will be identified at the posterior aspect of the esophagus and observed to be compressing its lumen and displacing the esophagus (Fig. 1). Endoscopy is used to rule out some other pathology, such as cancer or any condition that causes dysphagia. Manometry is not systematically requested, with the exception of patients with hiatal hernia, with reflux or when achalasia is suspected. On endoscopy, the endoscope natural entrance is observed to be directly onto the diverticulum, which is why we always suggest initially requesting an esophagus-gastroduodenal series, because the procedure can reach the diverticulum without observing the lumen and perforating it (Fig. 2).

Treatment for Zenker's diverticulum should be reserved for symptomatic patients. The purposes of treatment are to provide symptomatic relief and improve the quality of life. The treatment consists of transecting the cricopharyngeal muscle and elimination of the reservoir pouch of food and secretions, thus preventing them from accumulating. For this purpose, there are various surgical techniques:

- Open diverticulectomy + myotomy.

- Diverticulopexy + myotomy, which is preferred in small diverticula.

- Endoscopic myotomy.

- Diverticulum-esophagus anastomosis + transoral myotomy with stapler.

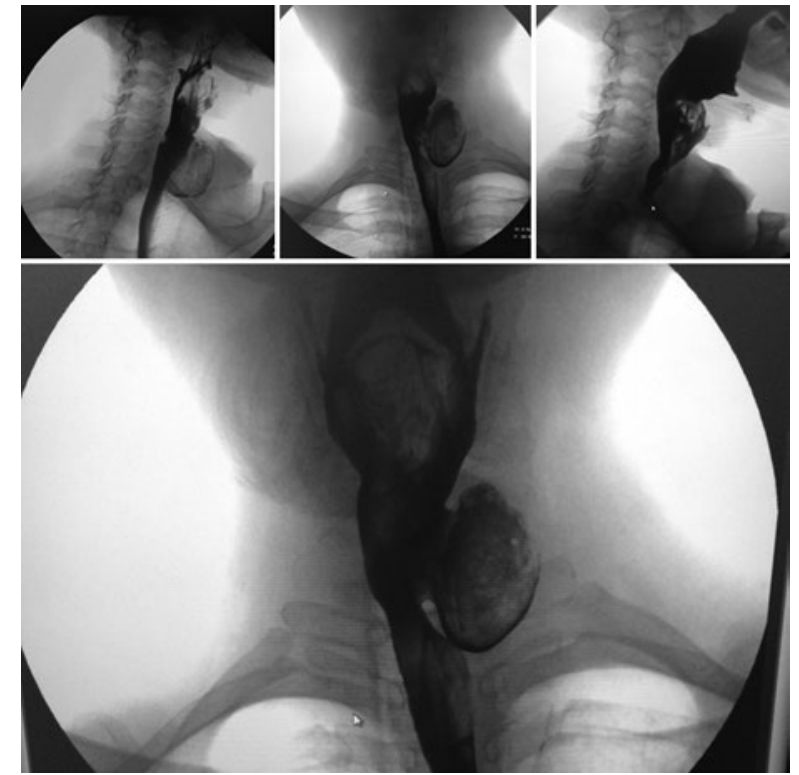

Figure 1. The esophagus-gastroduodenal series is the first diagnostic support study, where we will identify the diverticulum on the posterior aspect of the esophagus and observe how it will be compressing its lumen and displacing the esophagus.

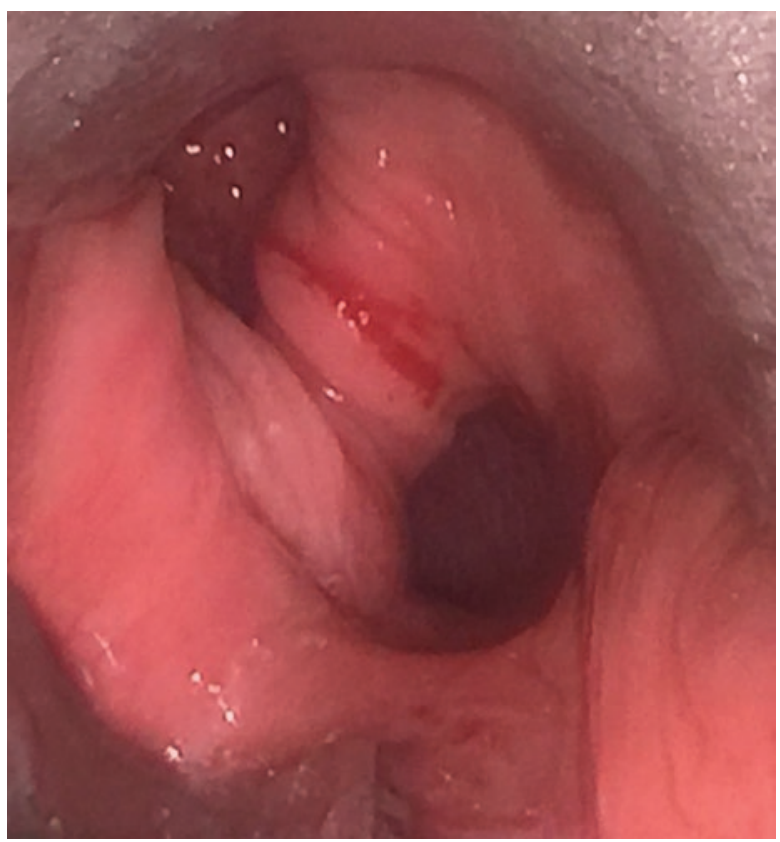

Figure 2. On endoscopy, we observe that the endoscope natural entrance is directly onto the diverticulum. In this image, the esophageal lumen is observed, separated from the diverticulum by a septum.

\section{Surgical technique}

In the open technique, we perform a Kocher-type incision, which provides good exposure and good esthetic results. We deepen by planes until reaching the anterior aspect of the esophagus and the prevertebral fascia, so that we can locate the diverticulum down to 
its bottom and we can adequately perform the diverticulectomy (Fig. 3), and subsequently the myotomy (of about 3-5 cm). Sometimes we carry out the diverticulectomy with a stapler, but we also have used suture. It is important not to put excessive traction on the diverticulum, because we can leave the patient with an esophageal stenosis. Another surgical option is diverticulopexy, where the diverticulum is sutured in the upper part, preventing it from functioning as a reservoir.

In the transoral endoscopic technique, the patient has to be positioned with the neck fully extended, so that elderly patients with significant limitation to fully extend the neck or with decreased buccal opening are excluded from this type of approach. With the patient under general anesthesia, the laryngoscope is introduced. The lumen that can be visualized is small, and thus this is a procedure with a high degree of difficulty (Fig. 4). When we observe the septum between the diverticulum and the esophagus, the stapler is introduced in said septum and complete myotomy is performed, with division of the common wall between the diverticulum and the esophagus, followed by immediate simultaneous closure of the divided borders with staples. We recommend placing two stitches with Endo Stitch ${ }^{\mathrm{TM}}$ on the cricopharyngeal septum, in order to properly fit the stapler and be sure that we have the entire cricopharyngeal muscle sectioned. It is important taking into account the length of the cricopharyngeal muscle, which is approximately $3 \mathrm{~cm}$; a diverticulum smaller than $3 \mathrm{~cm}$ contraindicates this approach, since the larger length of the stapler would yield an incomplete myotomy. Diverticulum-esophagus anastomosis + transoral myotomy with stapler is a technique with good esthetic results, since no skin incisions are performed, no drainage is left, there is no recurrent laryngeal nerve injury, it involves shorter hospital length of stay, and has lower morbidity and mortality. However, it is contraindicated for diverticula smaller than $3 \mathrm{~cm}$. Regarding the duration of the procedure, the world literature reports a trans-surgical time of 25 minutes, but, in our experience, we have a surgery duration of up to 60 minutes, due to the time consumed for adequate placement of the diverticuloscope and endoscope, in comparison with the open technique, which reports a duration of 60 to 90 minutes.

In a series of cases of 900 patients at the Mayo Clinic from 1944 to 1978, open treatment was reported to be successful in $93 \%$, with $3.6 \%$ of patients having recurrence, $1.2 \%$ infection, $1.8 \%$ fistula and $3.6 \%$

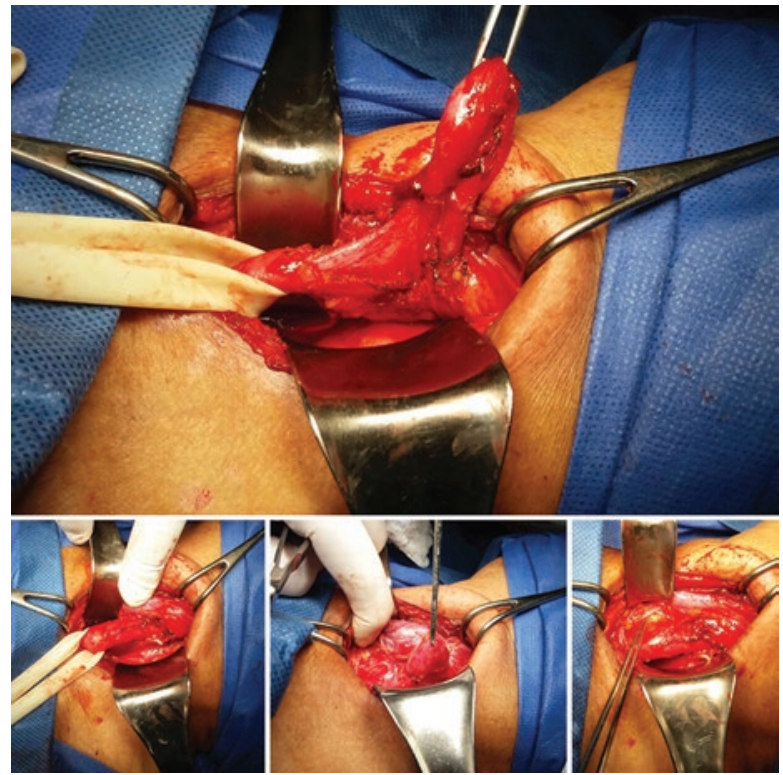

Figure 3. Diverticulectomy with open technique through a Kohler-type incision. Zenker's diverticulum is pulled with the help of the dissection forceps and the Penrose to identify the bottom.

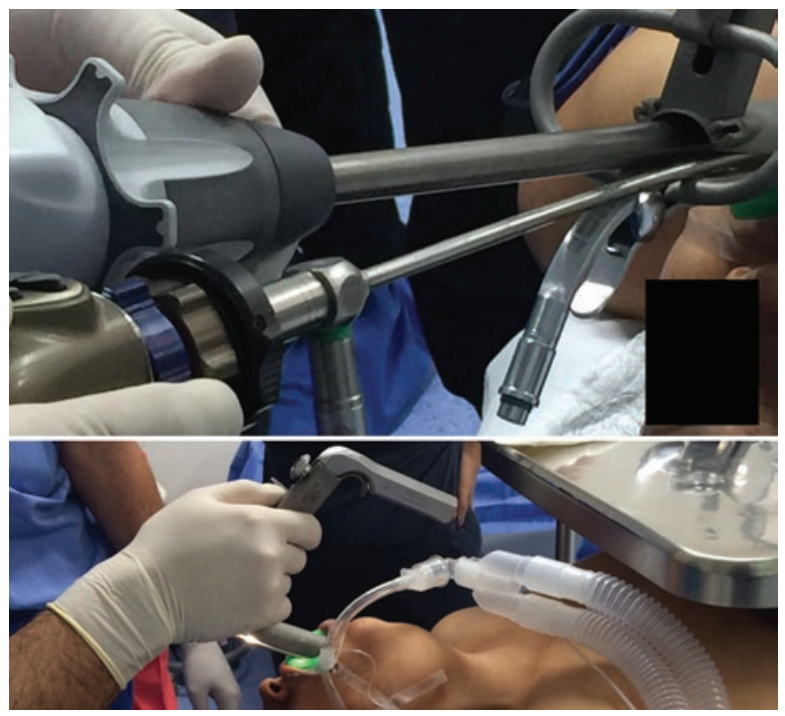

Figure 4. In the endoscopic technique, the patient has to be positioned with the neck fully extended. With the patient under general anesthesia, the laryngoscope is introduced. The lumen that can be visualized is small. When we observe the septum between the diverticulum and the esophagus, the stapler is introduced in the septum.

vocal cord paralysis due to recurrent laryngeal nerve injury, with a mortality of $1.2 \%{ }^{11}$.

In Italy, in the 1990s, in a series of 90 patients, the transoral technique was shown as a novel approach, with a 23-month follow-up being reported, with low rates of recurrence, zero morbidity and zero mortality ${ }^{12}$. Many authors refer to this technique as the treatment of choice. Recently, in the United Kingdom, one study reported intraoperative failure of $7.7 \%, 9.9 \%$ of complications and $12 \%$ of recurrence. ${ }^{13}$ 
In a systematic review that compared endoscopic versus open technique, higher rates of short-term failure, greater difficulty to obtain adequate access and fewer complications were observed with the transoral technique. However, mediastinitis can occur at a low percentage in comparison with the open technique, by means of which in no case are there problems to obtain adequate access to the diverticulum, although it has more complications (such as esophageal fistula), a decrease in quality of life is reported and hospital stay times are longer ${ }^{14}$. In a meta-analysis of 596 patients that compared endoscopic and surgical approaches, Albers et al. ${ }^{15}$ reported an improvement in the reduction of symptoms with surgery (standardized mean difference: 0.08; 95\% confidence interval $[\mathrm{Cl}]$ : 0.03-1.13), but higher complication rates (standardized mean difference: 0.09; 95\% Cl: 0.03-0.43). In particular, diverticulum size differences between groups were not subjected to heterogeneity evaluation.

The transoral endoscopic technique is a safe, effective and minimally invasive option to treat Zenker's diverticulum ${ }^{16-19}$, but only one study has provided longterm data ${ }^{20}$.

The popularity of this technique has catalyzed research and the development of accessories, technologies and operational approaches available to maximize the safety and efficacy profile. The meta-analysis by Ishaq et al. ${ }^{21}$ showed complication rates of $11.3 \%$ of cases, and recurrence of $11 \%$. Studies conducted prior to 2005 were associated with greater clinical success, but with high recurrence rates. This observation is interesting, especially when the quality of training and practice have considerably improved during this time. One possible explanation could be the lack of a single standardized technique. As technology for the treatment of this pathology evolves without an adequate volume of patients to develop surgeons' experience, the optimal combination of technique and device to achieve safety, efficacy and favorable long-term results remains unclear ${ }^{21}$.

Due to the relative infrequency of the condition, studies for its treatment are, at best, limited to small prospective studies, and there are no data from randomized controlled trials. There is a clear need for larger, well-designed, comparative prospective studies to assess the optimal method and treatment device, in order to allow training and practice standardization. In addition, universal outcome definitions, such as treatment success and relapse and complication rates, are necessary in order to allow a better comparison between studies and to guarantee the quality of practice.

Since the start of transoral technique, there has been no consensus on the training and technical aspects of therapy. As discussed in this study, the optimal technique remains controversial. For example, the importance of maintaining the oropharyngeal fascia intact during the septum incision, as recommended by Chang et al. ${ }^{22}$, has rarely been reported. Since Zenker's diverticulum is a rare disorder, training in therapeutic endoscopy can be a challenge, with an unknown learning curve. There is a clear need to ensure that training for a high-risk procedure has been of sufficient quality, and that the necessary technical competencies have been acquired prior to allowing unsupervised practice. Emphasis should begin with anatomical considerations. Since most domestic pigs have pharyngeal diverticula that resemble those in humans ${ }^{23}$, porcine models can be a useful tool for training and evaluation. A surgical simulator that demonstrates content and construct validity by allowing residents to acquire skills within a controlled environment to develop competency in Zenker's diverticulum therapy is also under development ${ }^{24}$.

The criteria we use at the upper GI tract clinic to decide the type of approach we are going to offer to our patient with Zenker's diverticulum include age (open surgery is preferred in young patients), neck mobility (patients with hyperextension limitations are excluded from transoral management), dentition (due to the possibility of dental injury when introducing the laryngoscope) and the availability of instruments to enable the use of the transoral technique.

\section{Conclusion}

In our institution, we observed that transoral stapling is a technique with good esthetic results, with resumption of oral intake on the same day of surgery and with shorter hospital stay. The sample is small, but in the experience of our clinic, the transoral approach is a technique with higher recurrence than open surgery, and therefore we suggest individualizing each case and maintaining long-term follow-up of patients.

\section{Conflicts of interest}

There are no conflicts of interest. 


\section{References}

1. Herrero A, Pérez L, Tejero-Garcés G, Guallar M, Orte C, Ortiz A. Tratamiento del divertículo de Zenker: comparación de diferentes técnicas. Acta Otorrinolaringol Esp. 2013;64:1-5.

2. Ludlow A. A case of obstructed deglutition, from a preternatural dilatation of, and bag formed in, the pharynx. Med Obs Inq. 1764;3:85-101.

3. Zenker FA, von Ziemssen H. Krankheiten des oesophagus. Handbuch der Speciellen Pathologie und Therapie. 7. Leipzig: Vogel; 1877.

4. Pérez Torres E, Pérez Pineda J. Diagnóstico y tratamiento del divertículo de Zenker. Rev Med Hosp Gen Mex. 2005;68:155-9.

5. Constantini M, Zaninoto G, Rizzetto C, Narne S, Ancona E. Oesophagea diverticula. Best Pract Res Clin Gastroenterol. 2004;18:3-17.

6. Cook IJ, Gabb M, Panagopoulos V, Jamieson GG, Dodds WJ, Dent J, et al. Pharingeal (Zenker's) diverticulum ia a disorder of upper esophageal sphincter opening. Gastroenterology. 1992;103:1229-35.

7. Gage-White L. Incidenca of Zenker's diverticulum with hiatus hernia. Laryngoscope. 1998;98:527-30.

8. Paterson WG, Kolyn DM. Esophageal shortening induced by short-term intraluminal acid perfusion in opossum; a cause for hiatus hernia? Gastroenterology. 1994;107:1736-40.

9. Sasaki CT, Ross DA, Hundal J. Association between Zenker diverticulum and gastroesophageal reflux disease: development of working hypotesis. Am J Med. 2003;115:169S-171S.

10. Feussner $H$, Siewert JR. Zenker's diverticulum and reflux. Hepatogastroenterology. 1992;32:95-6.

11. Payne WS. The treatment of pharyngoesophageal diverticulum: the simple and complex. Hepatogastroenterology. 1992;39:109-14.

12. Peracchia A, Bonavina L, Narne S, Segalin A, Antoniazzi L, Marotta G. Minimally invasive surgery for Zenker diverticulum: analysis of results in 95 consecutive patients. Arch Surg. 1998;133:695-700.
13. Leong SC, Wilkie MD, Webb CJ. Endoscopic stapling of Zenker's diverticulum: establishing national baselines for auditing clinical outcomes in the United Kingdom. Eur Arch Otorhinolaryngol. 2012;269:1877-84.

14. Johnson CM, Postma GN. Zenker diverticulum — which surgical approach is superior? JAMA Otolaryngol Head Neck Surg. 2016;142:401-3.

15. Albers DV, Kondo A, Bernardo WM, Sakai P, Moura RN, Silva GL, et al. Endoscopic versus surgical approach in the treatment of Zenker's diverticuum: systematic review and meta-analysis. Endosc Int Open. 2016:4:E678-86.

16. Law R, Katzka DA, Baron TH. Zenker's diverticulum. Clin Gastroenterol Hepatol. 2014;12:1773-82.

17. Verdonck J, Morton RP. Systematic review on treatment of Zenker's diverticulum. Eur Arch Otorhinolaryngol. 2015;272:3095-107.

18. Antonello A, Ishaq S, Zanatta L, Cesarotto M, Costantini M, Battaglia G. The role of flexible endotherapy for the treatment of recurrent Zenker's diverticula after surgery and endoscopic stapling. Surg Endosc. 2016;30:2351-7.

19. Aiolfi A, Scolari F, Saino G, Bonavina L. Current status of minimally invasive endoscopic management for Zenker diverticulum. World J Gastrointest Endosc. 2015;7:87-93.

20. Bonavina L, Aiolfi A, Scolari F, Bona D, Lovece A, Asti E. Long-term outcome and quality of life after transoral stapling for Zenker diverticulum. World J Gastroenterol. 2015;21:1167-72.

21. Ishaq S, Hassan C, Antonello A, Tanner K, Bellisario C, Battaglia G, et al. Flexible endoscopic treatment for Zenker's diverticulum: a systematic review and meta-analysis. Gastrointest Endosc. 2016;83:1076-89.e5.

22. Chang CWD, Liou SS, Netterville JL. Anatomic study of laser-assisted endoscopic cricopharyngeus myotomy. Ann Otol Rhinol Laryngol. 2005; 114:897-901.

23. Baron TH. Endoscopic management of Zenker diverticula. Gastroenterol Hepatol. 2017:13:242-4

24. Wiebracht ND, Giliberto JP, Myer C 4th, Casper K, Johnson KE. Pilot testing of a novel surgical simulator for endoscopic Zenker's diverticulotomy. Laryngoscope. 2017;127:592-6. 